\title{
Nyssorhynchus dunhami: bionomics and natural infection by Plasmodium falciparum and $P$. vivax in the Peruvian Amazon
}

\author{
Catharine Prussing1/ ${ }^{1}$, Sara A Bickersmith ${ }^{2}$, Marta Moreno ${ }^{3,}{ }^{,}$, Marlon P Saavedra ${ }^{4}$, Freddy Alava ${ }^{5}$, \\ Maria Anice Mureb Sallum ${ }^{6}$, Dionicia Gamboa ${ }^{4,7}$, Joseph M Vinetz ${ }^{3,4,7, * *}$, Jan E Conn ${ }^{1,2}$ \\ ${ }^{1}$ University at Albany, State University of New York, School of Public Health, Department of Biomedical Sciences, Albany, NY, USA \\ ${ }^{2}$ Wadsworth Center, New York State Department of Health, Albany, NY, USA \\ ${ }^{3}$ University of California San Diego, Department of Medicine, Division of Infectious Diseases, La Jolla, CA, USA \\ ${ }^{4}$ Universidad Peruana Cayetano Heredia, Facultad de Ciencias y Filosofia, Laboratorios de Investigación y Desarrollo, Laboratorio ICEMR- \\ Amazonia, Lima, Peru \\ ${ }^{5}$ Ministry of Health, Iquitos, Peru \\ ${ }^{6}$ Universidade de São Paulo, Faculdade de Saúde Pública, Departamento de Epidemiologia, São Paulo, SP, Brasil \\ ${ }^{7}$ Universidad Peruana Cayetano Heredia, Instituto de Medicina Tropical Alexander von Humboldt, Lima, Peru
}

BACKGROUND Nyssorhynchus dunhami, a member of the Nuneztovari Complex, has been collected in Brazil, Colombia, and Peru and described as zoophilic. Although to date $N y$. dunhami has not been documented to be naturally infected by Plasmodium, it is frequently misidentified as other Oswaldoi subgroup species that are local or regional malaria vectors.

OBJECTIVES The current study seeks to verify the morphological identification of Nuneztovari Complex species collected in the peri-Iquitos region of Amazonian Peru, to determine their Plasmodium infection status, and to describe ecological characteristics of their larval habitats.

METHODS We collected Ny. nuneztovari s.1. adults in 2011-2012, and Ny. nuneztovari s.1. larvae and adults in 2016-2017. When possible, samples were identified molecularly using cytochrome c oxidase subunit I (COI) barcode sequencing. Adult $N y$. nuneztovari s.l. from 2011-2012 were tested for Plasmodium using real-time PCR. Environmental characteristics associated with Ny. nuneztovari s.l. larvae-positive water bodies were evaluated.

FINDINGS We collected 590 Ny. nuneztovari s.1. adults and 116 larvae from eight villages in peri-Iquitos. Of these, 191 adults and 111 larvae were identified by $C O I$ sequencing; all were $N y$. dunhami. Three $N y$. dunhami were infected with $P$. falciparum, and one with $P$. vivax, all collected from one village on one night. $N y$. dunhami larvae were collected from natural and artificial water bodies, and their presence was positively associated with other Anophelinae larvae and amphibians, and negatively associated with people living within $250 \mathrm{~m}$.

MAIN CONCLUSIONS Of Nuneztovari Complex species, we identified only $N y$. dunhami across multiple years in eight periIquitos localities. This study is, to our knowledge, the first report of natural infection of molecularly identified $N y$. dunhami with Plasmodium. We advocate the use of molecular identification methods in this region to monitor Ny. dunhami and other putative secondary malaria vectors to more precisely evaluate their importance in malaria transmission.

Key words: Nyssorhynchus nuneztovari s.I. - Nyssorhynchus dunhami - Plasmodium - larval habitats - Peruvian Amazon

Nyssorhynchus nuneztovari s.l. (formerly named Anopheles nuneztovari s.1.) $)^{(1)}$ is a species complex consisting of at least four species: Ny. nuneztovari s.s. Gabaldón, 1940 (previously Ny. nuneztovari cytotypes B and $\mathrm{C}$ ), which has been found in Colombia and western Venezuela; Ny. nuneztovari cytotype A, from the western Brazilian Amazon (Sant'Ana et al., manuscript in preparation); Nyssorynchus goeldii Rozeboom \& Gabaldón, 1941, a genetically diverse species distributed

doi: 10.1590/0074-02760180380

Financial support: NIH-NIAID (U19AI089681) to JMV, NIH-NIAID (R01Al110112) to JEC, and WHO (TDR Contract 201460655) to DG.

The Biodefense and Emerging Infectious Disease training fellowship grant T32Al05532901 provided partial support for CP.

* Current affiliation: London School of Hygiene and Tropical Medicine,

Department of Immunology and Infection, London, UK.

** Current affiliation: Yale University School of Medicine,

Section of Infectious Diseases, New Haven, CT, USA

+ Corresponding author: cprussing@albany.edu

Received 8 August 2018

Accepted 30 October 2018 throughout the Brazilian Amazon; and Nyssorynchus dunhami Causey, 1945, recorded from the Brazilian, Colombian, and Peruvian Amazon. ${ }^{(1,2,3)}$ Members of this complex have been incriminated in malaria transmission in their endemic areas, though documentation of their vector status has been complicated by their morphological similarities and changes in taxonomic status..$^{(2,4,5)} \mathrm{Ny}$. nuneztovari s.s. is a major malaria vector in Colombia ${ }^{(6,7)}$ and Venezuela. ${ }^{(8,9,10)}$ Specimens of $N y$. nuneztovari s.l. have been found to be naturally infected with Plasmodium vivax and P. falciparum in the Brazilian Amazon and French Guiana, but documentation of the extent of their involvement in malaria transmission in these areas is fairly restricted. ${ }^{(11,12,13,14)}$

Ny. dunhami was first described in 1945, based on specimens collected in Tefé, Amazonas, Brazil. ${ }^{(15)}$ This species is morphologically similar to other species in the Nuneztovari Complex, and has been considered synonymous with, and subsequently resurrected from synonymy with, both $N y$. nuneztovari ${ }^{(16)}$ and Nyssorynchus trinkae Faran, 1979. ${ }^{(17)}$ It has been collected from Ama- 
zonas, ${ }^{(2,5,11,15,17,18)}$ Acre, ${ }^{(19)}$ Pará, ${ }^{(18)}$ and Rondônia ${ }^{(18)}$ states, Brazil; Amazonas department, Colombia; ${ }^{(20)}$ and Loreto department, Peru ${ }^{(21)}$ [Fig. 1; Supplementary data (Table I)]. Ny. dunhami is thought to be primarily zoophilic and has not been incriminated as a malaria vector. ${ }^{(2,22)}$ However, the geographic distributions of $N y$. dunhami, $N y$. goeldii, and $N y$. nuneztovari A overlap, ${ }^{(18)}$ and the reliance on morphological identification in previous reports of Plasmodium infection in $N y$. nuneztovari s.l. ${ }^{(23,24)}$ could confound our current understanding of the vector status of $N y$. dunhami.

In Peru, Ny. nuneztovari s.l. specimens have been reported from the departments of Pasco, Junín, Loreto, Ucayali, and Madre de Dios..$^{(25,26,27,28)}$ In addition, $N y$. trinkae, which was previously considered synonymous with $N y$. dunhami, ${ }^{(17)}$ was identified morphologically and found infected with Plasmodium in the Junín ${ }^{(29)}$ and Madre de Dios departments. ${ }^{(25)}$ In 2015, Ny. dunhami was first reported from the peri-Iquitos area of Loreto, Peru, ${ }^{(21)}$ where malaria is endemic and seasonal, and the primary vector is $N y$. darlingi Root, 1926. ${ }^{(21,28,30)}$. Despite the predominance of $N y$. darling $i$ in several Loreto department communities, other Anophelinae species, including $\mathrm{Ny}$. nuneztovari s.l. species, might be local or seasonal malaria vectors in this region. To investigate the vector status of the Nuneztovari Complex in Loreto, and inform future vector control efforts, the aims of the current study were to identify $N y$. nuneztovari s.l. species in the peri-Iquitos area, to determine their Plasmodium infection status, and to characterize their larval ecology.

\section{MATERIALS AND METHODS}

Adult mosquito collections: 2011-2012 - Adult Ny. nuneztovari s.1. mosquitoes were identified in the community of San José de Lupuna (LUP), as described previously. ${ }^{(21)}$ Adult human landing catch (HLC) collections were conducted inside and outside human dwellings (for the purposes of this paper, we define outside as in the peridomestic environment, within $10 \mathrm{~m}$ of a house), Shannon trap collections were conducted outside, and

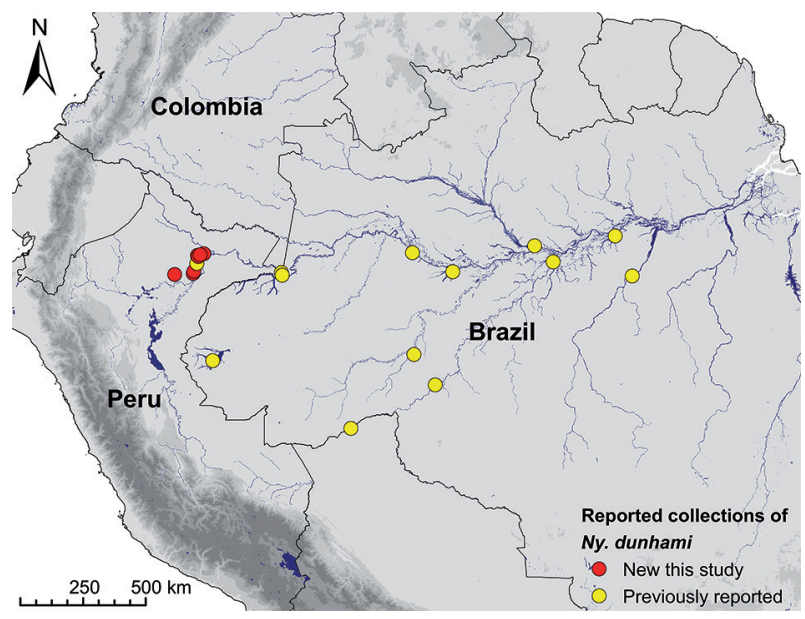

Fig. 1: all recorded collection locations of Nyssorhynchus dunhami, including the current study. Coordinates and references are listed in Supplementary data (Table I).
CDC light trap collections were conducted inside over 48 nights in LUP from 2011-2012. Details of collection methods are shown in Supplementary data (Table II). All mosquitoes were identified morphologically, ${ }^{(31,32,33)}$ then stored dry on silica gel until DNA extraction.

Larval and adult mosquito collections: 2016-2017 Collections of Anophelinae larvae and adults were conducted in eight villages in 2016-2017: LUP on the Nanay River, Nuevo Horizonte (NHO) and El Triunfo (TRI) on the Iquitos-Nauta Highway, Santa Emilia (SEM) on the Nahuapa Stream, Salvador (SAL) and Urco Miraño (URC) on the Napo River, and Libertad (LIB) and Visto Bueno (VIB) on the Mazan River [Fig. 2; coordinates in Supplementary data (Table I)]. In LUP, NHO, TRI, and SEM, six collections were conducted, and in SAL, URC, LIB, and VIB, five collections were conducted (Table I).

All potential larval habitats within a $1 \mathrm{~km}$ radius of each village were identified on satellite images and by ground-truthing, for a total of 88 water bodies in the eight villages. The $1 \mathrm{~km}$ distance was chosen to correspond approximately with the flight range of $N y$. darlingi, the primary target of the larval collections. ${ }^{(34)}$ Each water body was sampled for Anophelinae larvae once per collection. Dips with standard $350 \mathrm{~mL}$ capacity dippers were taken 10 meters apart along the perimeter of each water body, with at most 20 dipping locations per site. At each dipping location, 10 dips were taken and examined for the presence of Anophelinae larvae.

Larvae from LUP, NHO, TRI, and SEM were reared to adults for morphological species identification. All larvae that died before reaching adulthood, that were unable to be identified, or that were identified as non- $N y$. darlingi, were preserved for DNA extraction and molecular identification in $100 \%$ ethanol (larvae) or on silica gel (adults). All larvae from SAL, URC, LIB, and VIB were killed and preserved in $100 \%$ ethanol for molecular identification.

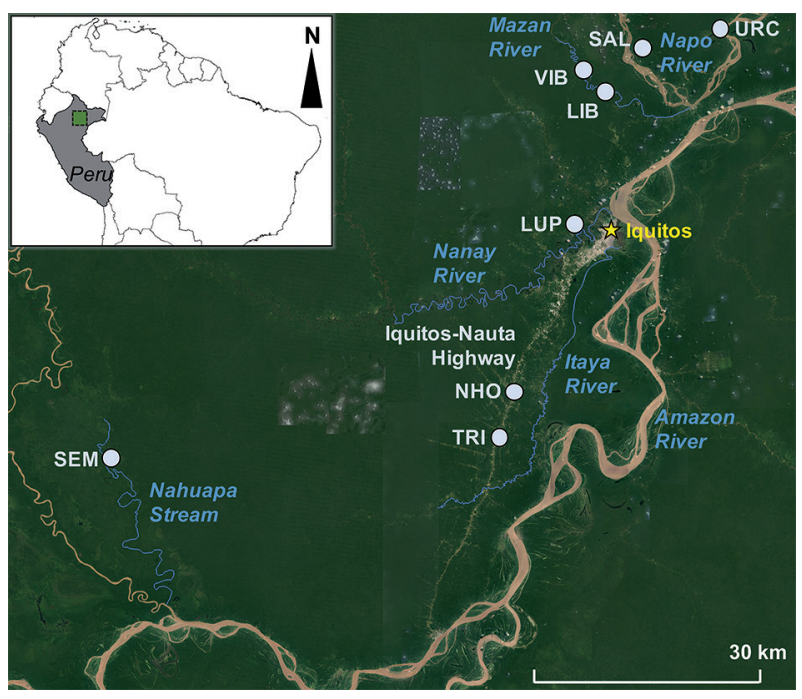

Fig. 2: collection sites of adult and larval Nyssorhynchus nuneztovari s.1. in peri-Iquitos, 2011-2012 and 2016-2017. LUP: Lupuna; NHO: Nuevo Horizonte; TRI: El Triunfo; SEM: Santa Emilia; SAL: Salvador; URC: Urco Miraño; LIB: Libertad; VIB: Visto Bueno. 
TABLE I

Dates of 2016-17 larval and adult collections in eight villages in peri-Iquitos, Peru

\begin{tabular}{lcc}
\hline Collection & LUP, NHO, TRI, and SEM & SAL, URC, LIB, and VIB \\
\hline 1 & January/February 2016 (rainy season) & March 2016 (rainy season) \\
2 & April 2016 (rainy season) & June 2016 (rainy season) \\
3 & July/August 2016 (dry season) & September 2016 (dry season) \\
4 & September/October 2016 (dry season) & November 2016 (dry season) \\
5 & November/December 2016 (dry season) & February/March 2017 (rainy season) \\
6 & January-March 2017 (rainy season) & \\
\hline
\end{tabular}

LUP: Lupuna; NHO: Nuevo Horizonte; TRI: El Triunfo; SEM: Santa Emilia; SAL: Salvador; URC: Urco Miraño; LIB: Libertad; VIB: Visto Bueno.

Water body characteristics, including water body type, depth, cloud cover, light intensity (using a Foot Candle/Lux meter, Extech, Nashua, NH, USA), shade level, presence of vegetation, shade, presence of fish and amphibians, and type of water bed material, were recorded at each water body at each collection. In addition, chemical characteristics, including alkalinity, hardness, and nitrate and nitrite levels (using Eco-Check 5-in-1 Test Strips, Industrial Test Systems, Inc., Rock Hill, SC, USA); and pH, temperature, conductivity, and salinity (using an ExStik $\mathrm{pH} /$ Conductivity Meter, Extech, Nashua, NH, USA), were measured for each water body at each collection.

Concurrent with larval collections in SAL, URC, LIB, and VIB, adult mosquitoes were collected by HLC (12-hour collections inside and outside from 6 pm-6 am, two nights per month) and barrier screens (12-hour collections from 6 pm- 6 am, one night per month) (Saavedra et al., manuscript in preparation). All adult mosquitoes collected that were initially morphologically identified as non- $N y$. darlingi were molecularly identified.

DNA extraction and molecular identification - Total genomic DNA was extracted from the head/thorax of adult female mosquitoes, and from whole mosquito larvae and whole adults reared from larvae, using the DNeasy Blood \& Tissue kit (Qiagen, Hilden, Germany). Mosquitoes were identified using polymerase chain reaction-restriction fragment length polymorphism (PCRRFLP) of the ribosomal internal transcribed spacer 2 (ITS2) region, ${ }^{(26)}$ or by sequencing the barcode region of the cytochrome c oxidase subunit I (COI) gene. ${ }^{(35,36)}$ For each sample, the barcode region was sequenced in one direction using the forward primer by the Wadsworth Center Applied Genomic Technologies Core (New York State Department of Health). The sequences were queried against the BOLD Identification System ${ }^{(37)}$ or GenBank (https://www.ncbi.nlm.nih.gov/genbank/).

Testing for Plasmodium infection - All heads/thoraces of adult mosquitoes collected in 2011-2012 and molecularly identified as $N y$. nuneztovari s.l. were tested for Plasmodium infection by real-time PCR of the small subunit of the 18S rRNA gene, as described previously. (38) All mosquitoes were tested individually for $P$. falciparum and $P$. vivax using a triplex TaqMan assay (Life Technologies, Carlsbad, CA, USA).
Larval site characteristics statistical analysis - Analysis of the characteristics associated with the presence of $N y$. nuneztovari s.l. larvae in water bodies was conducted in $\mathrm{R} v$. 3.5.0 $0^{(39)}$ at the level of the water body with a dataset that included one entry for each water body at each time point. Entries for water bodies that were dry at the time of collection were excluded from the final analysis. Water bodies that were dry at one or more collections were considered temporal, otherwise, they were considered permanent. Potential variables included locality, quarter (January-March 2016, April-June 2016, etc.), water body type (active fishpond vs. abandoned fishpond or natural site); presence of trees, bushes, grass, algae, emergent vegetation, floating vegetation, fish, and amphibians; presence of non-Ny. nuneztovari s.1. Nyssorhynchus, Stethomyia, or Anopheles spp. larvae; shade level (total, partial, or none); cloud cover (cloudy or not); bed material (sand, organic, mixed, or mud); water movement (moving or not); water body seasonality (temporal or permanent); depth; alkalinity; conductivity; hardness; light intensity; $\mathrm{pH}$; salinity; and temperature. Nitrate and nitrite levels were not included because of the very low frequency of non-zero measurements $(0.7 \%$ and $0.2 \%$, respectively).

Censuses, including the GIS coordinates of each inhabited house, were completed in each village in May 2015 (SEM), November 2015 (LUP), or November/December 2016 (all other villages). Using these data, the distance from each water body to the nearest inhabited house, and the number of people living within 50, 100, 250 , and $500 \mathrm{~m}$ radius buffers from each body were calculated using the R packages $\operatorname{sp}^{(40)}$ and rgeos. ${ }^{(41)}$ Additionally, presence/absence variables for whether any people lived within each buffer were calculated. As it was not known which, if any, population density measurement at which radius could affect $N y$. nuneztovari s.l. presence, bivariate models were built for each value at each radius, and the variable with the highest bivariate $\log$ likelihood was selected. There was a small amount of missing data in the analysis dataset (2\% total, $8 \%$ or less for each variable). To account for missing data, multiple imputation was completed using the $\mathrm{R}$ package mice $^{(42)}$ (five imputations, 20 iterations each).

Logistic mixed-effects models were constructed using the imputed datasets with the $\mathrm{R}$ package mitml, ${ }^{(43)}$ using the presence of $N y$. nuneztovari s.l. as the out- 
come, and the water body ID as the random intercept to account for multiple collections at the same water body. Bivariate models were used to assess the relationship between each variable and the presence of $N y$. nuneztovari s.l. The multivariate model was built using a forward stepwise procedure, adding each variable with bivariate $\mathrm{p}<0.2$ in order of its bivariate log likelihood and retaining variables if $\mathrm{p}<0.1$ in the final model.

COI sequence analysis and haplotype network - COI sequences of adult and larval $N y$. nuneztovari s.l. from the current study ( $\mathrm{n}=315$ of 706 specimens) were edited and checked for stop codons and pseudogenes in Geneious v9.1.4. ${ }^{(44)}$ Additional $C O I$ sequences were retrieved from GenBank [Supplementary data (Table V)] for $N y$. dunhami $(\mathrm{n}=12), N y$. goeldii $(\mathrm{n}=6)$, and Ny. nuneztovari s.l. $(\mathrm{n}=43)$. All sequences were aligned with MUSCLE ${ }^{(45)}$ using default settings and trimmed in MEGA7 v7.0.26(46) to the length of the shortest sequence (446 bp). PopART v1. $7^{(47)}$ was used to construct a median-joining haplotype network, ${ }^{(48)}$ with epsilon set to 0 . Unique sequences for each haplotype containing new sequences from this study have been deposited in GenBank under accession numbers MH723612 to MH723701.

Ethics - This study was approved by the Human Subjects Protection Program of the University of California San Diego, La Jolla, and by the Ethical Boards of Universidad Peruana Cayetano Heredia and Asociación Benéfica PRISMA, Lima, Peru.

\section{RESULTS}

Adult mosquito collections and Plasmodium infection: 2011-2012 - A total of 587 Ny. nuneztovari s.l. adults were collected from LUP in 2011-2012 (Table II). Of these, 273 (47\%) were confirmed as $N y$. nuneztovari s.l. by ITS2 PCR-RFLP. The remaining 314 (53\%) were not able to be molecularly identified because the specimen was lost in processing or the ITS2 PCR product did not amplify. Additionally, 27 specimens identified morphologically as non-Ny. nuneztovari s.l. were determined to be $N y$. nuneztovari s.l. by ITS2 PCR-RFLP. The initial morphological identification of specimens as $N y$. nuneztovari s.l. was robust: 246 (95\%) of 259 morphologically identified Ny. nuneztovari s.l. that could be identified by ITS2 PCR-RFLP were confirmed to be $N y$. nuneztovari s.l. The remaining 13 specimens were identified as $N y$. darlingi $(\mathrm{n}=6), N y$. benarrochi $\mathrm{B}(\mathrm{n}=3)$, or $N y$. oswaldoi s.l. $(\mathrm{n}=3)$; or were unable to be identified $(\mathrm{n}=1)$.

Nearly all collected $N y$. nuneztovari s.l. adults (579, 99\%) were captured outside by HLC or Shannon trap. Since we conducted a mixture of 4- and 12-hour collections, a comprehensive analysis of biting time could not be completed. However, during sampling in February and April 2011, 175 (82\%) of 214 Ny. nuneztovari s.l. collected by outdoor HLC, and 225 (64\%) of 349 by outdoor Shannon trap, were captured between 6-8 pm [Supplementary data (Table IV)].

Of the 273 mosquitoes identified by ITS2 PCRRFLP as Ny. nuneztovari s.1., 270 (99\%) were tested for Plasmodium. Four specimens, all collected on February 24, 2011 from 6-7 pm by outdoor HLC, were infected, three with $P$. falciparum and one with $P$. vivax [Table II, Supplementary data (Table IV)]. A total of 13 Ny. nuneztovari s.1. tested for Plasmodium were collected from 6-7 $\mathrm{pm}$ on this night (infection rate $=0.31$ ).

Larval and adult mosquito collections: 2016-2017 A total of 1,737 molecularly identified Nyssorhynchus, Stethomyia, and Anopheles larvae were collected in 20162017; of these, 116 (7\%) were $N y$. nuneztovari s.1., collected from 38 water bodies in all eight villages. These water bodies included active fishponds $(\mathrm{n}=17)$, streams/ rivers (14), lagoons (2), swamps (2), abandoned fishponds (2) and puddles (1) [Supplementary data (Table III)].

Excluding 84 collection points at which the water body was dry, there were a total of 403 collection points (water bodies sampled at a time point). Of these, $68(17 \%)$ were positive for $N y$. nuneztovari s.l. Using bivariate logistic mixed-effects regression, the presence of $\mathrm{Ny}$. nuneztovari s.l. was positively associated with ( $\mathrm{p}$ $<0.2$ ) the presence of non-Ny. nuneztovari s.l. Anophelinae species, fish, amphibians, and grass; active fishponds vs. natural water bodies or abandoned fishponds; and partial or total shade; and negatively associated with temporal vs. permanent water bodies and the presence of people in a $250 \mathrm{~m}$ radius. In addition, the lowest odds of Ny. nuneztovari s.l. presence was in the January-March quarter (the beginning of the rainy season), particularly in 2017. In the multivariate model, the only variables associated with the presence of $N y$. nuneztovari s.l. $(\mathrm{p}<$ 0.1 ) were quarter of the year, the presence of non- $N y$. nuneztovari s.l. larvae and amphibians, and the absence of people living in a $250 \mathrm{~m}$ radius (Table III).

Only three adult mosquitoes collected in 2016-2017 were identified as $N y$. nuneztovari s.l. by ITS2 PCRRFLP: one by outdoor HLC in LIB in March 2016, and two by barrier screen in URC in June 2016. These adults were not tested for Plasmodium infection.

COI sequence analysis and haplotype network - COI barcode region sequences were obtained for $315(80 \%)$ of 392 adults and larvae identified by ITS2 PCR-RFLP as $N y$. nuneztovari s.l. After discarding 13 low-quality sequences, 363 sequences were retained in the final analysis (from 188 adults collected in 2011-2012, including all four Plasmodium-infected adults; all three adults collected in 2016; and 111 larvae collected in 2016-2017). There were 123 haplotypes: 85 included only sequences from this study, five included sequences both from this study and GenBank sequences identified as $N y$. dunhami, five included only GenBank sequences identified as $N y$. dunhami, and 28 included a combination of GenBank sequences identified as $N y$. nuneztovari s.l. and $N y$. goeldii [Supplementary data (Table V)]. The haplotypes including samples from the present study and $N y$. dunhami GenBank sequences grouped separately from those including $N y$. nuneztovari s.l. and $N y$. goeldii GenBank sequences [Supplementary data (Figure)], indicating that the samples from the present study were all $N y$. dunhami.

\section{DISCUSSION}

This study provides further confirmation of the presence of Ny. dunhami in Peru, and extends its distribution into seven villages in the peri-Iquitos area in addition to 
TABLE II

Adult Nyssorhynchus nuneztovari s.l. collected in Lupuna (LUP), 2011-2012

\begin{tabular}{|c|c|c|c|}
\hline Month & Collection method & $\begin{array}{c}\text { Total } \mathrm{n}^{\circ} \text { of } N y . \text { nuneztovari } \text { s.l. collected } \\
\left(\mathrm{n}^{\circ} \text { confirmed as } N y . \text { nuneztovari } \mathrm{s} .1 .\right. \\
\text { by ITS2 PCR-RFLP) }\end{array}$ & $\begin{array}{c}\mathrm{N}^{\mathrm{o}} \text { of } N y . \text { nuneztovari s.l. } \\
\text { confirmed as } N y \text {. dunhami by } C O I \\
\text { sequence analysis }\end{array}$ \\
\hline \multirow[t]{3}{*}{ February 2011} & Human landing catch: inside & $1(0)$ & 0 \\
\hline & Human landing catch: outside & $51(21)$ & $20^{*}$ \\
\hline & Shannon trap: outside & $147(30)$ & 27 \\
\hline \multirow[t]{3}{*}{ April 2011} & CDC light trap: inside & $5(4)$ & 4 \\
\hline & Human landing catch: outside & $163(87)$ & 60 \\
\hline & Shannon trap: outside & $202(130)$ & 77 \\
\hline June 2011 & Human landing catch: outside & $2(0)$ & 0 \\
\hline \multirow[t]{3}{*}{ October 2011} & Human landing catch: inside & $1(0)$ & 0 \\
\hline & Human landing catch: outside & $4(0)$ & 0 \\
\hline & Shannon trap: outside & $1(0)$ & 0 \\
\hline \multirow[t]{2}{*}{ December 2011} & Human landing catch: outside & $4(0)$ & 0 \\
\hline & Shannon trap: outside & $1(0)$ & 0 \\
\hline \multirow[t]{2}{*}{ February 2012} & Human landing catch: inside & $1(0)$ & 0 \\
\hline & Human landing catch: outside & $3(0)$ & 0 \\
\hline June 2012 & Human landing catch: outside & $1(1)$ & 0 \\
\hline Total & & $587(273)$ & 188 \\
\hline
\end{tabular}

*: three infected with Plasmodium falciparum, one infected with P. vivax; COI: cytochrome c oxidase subunit I; PCR-RFLP: polymerase chain reaction-restriction fragment length polymorphism.

LUP. $^{(21)}$ Though we cannot rule out the presence of other $N y$. nuneztovari s.l. species in this area, all $N y$. nuneztovari s.l. mosquitoes that we identified by COI sequencing from these eight villages (191 adults and 111 larvae) were $N y$. dunhami. As morphological keys are unable to differentiate between $N y$. dunhami and other $N y$. nuneztovari s.l. species, it is possible that other reports of $N y$. nuneztovari from Loreto ${ }^{(25,27,28)}$ were also $N y$. dunhami. Additionally, the morphologically similar Ny. trinkae ${ }^{(20)}$ has been reported infected with Plasmodium in the Junín and Madre de Dios Departments of Peru; ${ }^{(25,29)}$ molecular identification methods could be used to determine whether some or all of these specimens, if available, were instead $N y$. dunhami.

This study is the first report of natural infection of molecularly identified $N y$. dunhami with Plasmodium. The four infected mosquitoes were all collected from the same village during the same hour of one night. It is possible that the infection of these Ny. dunhami with Plasmodium was an unusual event precipitated by the high densities of $\mathrm{Ny}$. dunhami present in LUP in February and April 2011. These densities corresponded with an unusually high infection rate $(5.88 \%)$ of $N y$. darlingi in February 2011 in LUP, and an unusually high human biting rate (757 bites per person per night) of $N y$. darlingi in April 2011 in LUP, despite relatively low numbers of malaria cases in the village in these months. ${ }^{(21)}$ Although we have continued longitudinal sampling of adult Anophelinae mosquitoes by multiple methods in several villages in peri-Iquitos, including LUP, since $2011,{ }^{(49,50)}$ we have not collected large numbers of $N y$. dunhami in any village since April 2011. It is possible that some unknown environmental condition conducive for $N y$. dunhami reproduction or survival in LUP occurred in 2011. However, our identification of low densities of $N y$. dunhami larvae and adults in eight villages in peri-Iquitos in 2016-2017 indicates that this species is established in the region, and its potential to be naturally infected with both $P$. vivax and $P$. falciparum suggests that it may be acting as a local or regional secondary malaria vector in peri-Iquitos.

This study was not designed to comprehensively investigate the biting behavior of $N y$. dunhami. However, our ability to collect this species by HLC and its infection with human Plasmodium species confirms that it does blood-feed on humans. In addition, the majority of Ny. nuneztovari s.l. in this study were collected in the peridomestic environment from 6-8 pm. This exophagic and early evening biting behavior is consistent with results of other studies of $N y$. nuneztovari s.l. species in the Amazon, ${ }^{(22,25,51,52)}$ and might indicate that $N y$. nuneztovari s.l. species are contributing to residual malaria transmission in peri-Iquitos.

The larval habitat of $N y$. dunhami has not been previously described. We collected $N y$. nuneztovari s.l. larvae (over $95 \%$ of which were confirmed to be $N y$. dunhami) from both artificial and natural water bodies in both the rainy and dry seasons. This diversity of larval habitats is consistent with reports of $N y$. nuneztovari s.1., ${ }^{(32)}$ and of Ny. nuneztovari s.s. in Colombia and Venezuela. ${ }^{(6,8,53)}$. In the current study, $N y$. dunhami larval habitats were positively associated with the presence of amphibians and other Anophelinae species, and negatively associated 


\section{TABLE III}

Logistic mixed-effects regression for the presence of Nyssorhynchus nuneztovari s.l. larvae in eight localities in peri-Iquitos, 2016-2017

\begin{tabular}{|c|c|c|c|c|}
\hline Variable* & $\begin{array}{l}\text { Bivariate OR } \\
(95 \% \mathrm{CI})\end{array}$ & $\begin{array}{l}\text { Bivariate } \\
\text { p-value }\end{array}$ & $\begin{array}{l}\text { Multivariate OR } \\
\qquad(95 \% \mathrm{CI})\end{array}$ & $\begin{array}{c}\text { Multivariate } \\
\text { p-value }\end{array}$ \\
\hline Intercept & - & - & $0.01(0.002,0.04)$ & $<0.001$ \\
\hline Non-Ny. nuneztovari s.l. Anophelinae species present & $16.76(6.92,40.62)$ & $<0.001$ & $19.94(8.00,49.68)$ & $<0.001$ \\
\hline $\begin{array}{l}\text { Active fishpond } \\
\text { (ref = natural water body or abandoned fishpond) }\end{array}$ & $4.68(2.08,10.53)$ & $<0.001$ & - & - \\
\hline Fish present & $3.65(1.11,12.02)$ & 0.039 & - & - \\
\hline Amphibians present & $2.58(1.32,5.03)$ & 0.006 & $2.27(1.20,4.29)$ & 0.012 \\
\hline \multicolumn{5}{|l|}{ Quarter (ref = January-March 2017: rainy season) } \\
\hline January-March 2016 (rainy season) & $3.15(0.98,10.19)$ & 0.055 & $3.42(1.06,11.05)$ & 0.040 \\
\hline April-June 2016 (rainy season) & $4.70(1.49,14.85)$ & 0.008 & $7.65(2.34,25.00)$ & 0.001 \\
\hline July-September 2016 (dry season) & $4.16(1.28,13.51)$ & 0.018 & $6.15(1.85,20.44)$ & 0.003 \\
\hline October-December 2016 (dry season) & $4.12(1.33,12.75)$ & 0.014 & $4.45(1.43,13.82)$ & 0.010 \\
\hline Grass present & $2.77(1.13,6.79)$ & 0.026 & - & - \\
\hline Any people living in a $250 \mathrm{~m}$ radius & $0.42(0.18,0.99)$ & 0.048 & $0.33(0.16,0.67)$ & 0.002 \\
\hline Temporal water body (ref = permanent) & $0.49(0.22,1.12)$ & 0.090 & - & - \\
\hline \multicolumn{5}{|l|}{ Shade level $($ ref $=$ none $)$} \\
\hline Partial shade & $2.11(0.76,5.83)$ & 0.150 & - & - \\
\hline Total shade & $2.51(0.83,7.56)$ & 0.102 & - & - \\
\hline
\end{tabular}

*: variables not associated with the presence of $N y$. nuneztovari s.l. (bivariate logistic mixed-effects regression $\mathrm{p}>0.2$ ): alkalinity; bed material; cloud cover; conductivity; depth; hardness; light intensity; locality; $\mathrm{pH}$; salinity; temperature; presence of algae, bushes, emergent vegetation, floating vegetation, trees, water movement. CI: confidence interval; OR: odds ratio.

with the presence of human dwellings within $250 \mathrm{~m}$. This negative association with humans could be explained by previous reports that $N y$. dunhami is primarily zoophagic. (22,51) Alternatively, water bodies located far from houses could be more suitable for $\mathrm{Ny}$. dunhami oviposition or larval survival due to environmental characteristics not measured during this study or not significantly different in $\mathrm{Ny}$. dunhami negative and positive sites due to the relatively small number of positive water bodies. Future research characterizing $N y$. dunhami habitats and host preference could distinguish between these possibilities.

The results of this study highlight the necessity of combining molecular identification techniques with morphological identification when studying the ecology of species in the Nuneztovari Complex. As many countries in South America work towards malaria elimination, it will be essential to increase knowledge of potential local and regional secondary vectors, including $N y$. dunhami, a task that will require both continued testing of multiple species for Plasmodium infection and accurate identification of the mosquito species involved in malaria transmission.

\section{ACKNOWLEDGEMENTS}

To Carlos Valderrama, David Arimuya, Mario Florez, Sandi Mamerto, Hercules Maytahuari, Victor Pacaya, Eliseo Ramirez, Dicla Ramos, José Manuel Reyna, Gloria Rodriguez, Santiago Ruiz, Papa Segundo, Papa Wilson, and Roberto Wong for assistance with field work. We also thank Carlos Tong and Carlos Valderrama for morphological identifications, and Gabriel Carrasco-Escobar for helpful advice on the larval habitat analysis. We are grateful to the Dirección Regional de Salud (DIRESA, Iquitos, Loreto) for collaboration in the Loreto Department, and to the communities of Lupuna, Libertad, Nuevo Horizonte, Salvador, Santa Emilia, El Triunfo, Urco Miraño, and Visto Bueno for their support. This publication is possible thanks to the authorization and permits N. 0424-2012-AG-DGFFS-DGEFFS from the Dirección de Gestión Forestal y de Fauna Silvestre and the Dirección General Forestal y de Fauna Silvestre of the Ministerio de Agricultura de la República del Perú.

\section{AUTHORS' CONTRIBUTION}

$\mathrm{CP}$ wrote the manuscript with contributions from JEC, MAMS, and JMV; MM, MPS and FA collected field data; DG helped oversee field collections; SAB and CP conducted molecular work and data analysis. All authors read and approved the final manuscript.

\section{REFERENCES}

1. Foster PG, de Oliveira TMP, Bergo ES, Conn JE, Sant'Ana DC, Nagaki SS, et al. Phylogeny of Anophelinae using mitochondrial protein coding genes. R Soc Open Sci. 2017; 4(11): 170758.

2. Scarpassa VM, Cunha-Machado AS, Saraiva JF. Evidence of new species for malaria vector Anopheles nuneztovari sensu lato in the Brazilian Amazon region. Malar J. 2016; 15: 205.

3. Foster PG, Bergo ES, Bourke BP, Oliveira TM, Nagaki SS, Sant'Ana DC, et al. Phylogenetic analysis and DNA-based species confirmation in Anopheles (Nyssorhynchus). PLoS One. 2013; 8(2): e54063.

4. Gómez G, Cienfuegos A, Gutiérrez L, Conn J, Correa M. Análisis morfológico y molecular evidencia problemas al identificar Anopheles nuneztovari (Diptera: Culicidae) por claves dicotómicas. Rev Col Ent. 2010; 36: 68-75. 
5. Calado DC, Foster PG, Bergo ES, dos Santos CLS, Galardo AKR, Sallum MAM. Resurrection of Anopheles goeldii from synonymy with Anopheles nuneztovari (Diptera, Culicidae) and a new record for Anopheles dunhami in the Brazilian Amazon. Mem Inst Oswaldo Cruz. 2008; 103(8): 791-9.

6. Naranjo-Díaz N, Sallum MAM, Correa MM. Population dynamics of Anopheles nuneztovari in Colombia. Infect Genet Evol. 2016; 45: 56-65.

7. Gutiérrez LA, González JJ, Gómez GF, Castro MI, Rosero DA, Luckhart S, et al. Species composition and natural infectivity of anthropophilic Anopheles (Diptera: Culicidae) in the states of Cordoba and Antioquia, Northwestern Colombia. Mem Inst Oswaldo Cruz. 2009; 104(8): 1117-24.

8. Moreno JE, Rubio-Palis Y, Sánchez V, Mariany D. [Primer registro de Anopheles (Nyssorhynchus) nuneztovari Gabaldón, 1940 (Diptera: Culicidae) en el estado Bolívar, Venezuela y sus implicaciones eco-epidemiológicas]. Entomotropica. 2004; 19(1): 55-8.

9. Rubio-Palis Y. Anopheles (Nyssorhynchus) de Venezuela: taxonomía, bionomía, ecología e importancia médica. Escuela de Malariología y Saneamiento Ambiental Dr. Arnoldo Gabaldon y el Proyecto Control de Enfermedades Endémicas. Maracay: 2000. 120 pp.

10. Orm SA, Moreno JE, Carrozza M, Acevedo P, Herrera F. Plasmodium spp. infection rates for some Anopheles spp. from Sifontes municipality, Bolívar state, Venezuela. Bol Malariol Salud Amb. 2017; LVII(1): 17-25.

11. Trindade DB, Scarpassa VM. Genetic differentiation and diagnostic loci among Anopheles (Nyssorhynchus) rangeli, An. (Nys.) nuneztovari, and An. (Nys.) dunhami (Diptera: Culicidae) in the Brazilian Amazon. J Med Entomol. 2002; 39(4): 613-20.

12. Galardo AK, Arruda M, Couto AAD, Wirtz R, Lounibos LP, Zimmerman RH. Malaria vector incrimination in three rural riverine villages in the Brazilian Amazon. Am J Trop Med Hyg. 2007; 76(3): 461-9.

13. Sant'Ana DC, Bergo ES, Sallum MAM. Anopheles goeldii Rozeboom \& Gabaldón (Diptera, Culicidae): a species of the Nuneztovari Complex of Anopheles Meigen. Rev Bras Entomol. 2015; 59: 68-76.

14. Dusfour I, Issaly J, Carinci R, Gaborit P, Girod R. Incrimination of Anopheles (Anopheles) intermedius Peryassú, An. (Nyssorhynchus) nuneztovari Gabaldón, An. (Nys.) oswaldoi Peryassú as natural vectors of Plasmodium falciparum in French Guiana. Mem Inst Oswaldo Cruz. 2012; 107(3): 429-32.

15. Causey OR. Description of Anopheles (Nyssorhynchus) dunhami, a new species from the Upper Amazon Basin. J Natl Malar Soc. 1945; 4(3): 231-4.

16. Peyton EL. Anopheles (Nyssorhynchus) dunhami, resurrected from synonymy with Anopheles nuneztovari and validated as a senior synonym of Anopheles trinkae (Diptera: Culicidae). Mosq Syst. 1993; 25(3): 151-6.

17. Lounibos LP, Wilkerson RC, Conn JE, Hribar LJ, Fritz GN, Danoff-Burg JA. Morphological, molecular, and chromosomal discrimination of cryptic Anopheles (Nyssorhynchus) (Diptera: Culicidae) from South America. J Med Entomol. 1998; 35(5): 830-8.

18. Scarpassa VM, Conn JE. Mitochondrial DNA detects a complex evolutionary history with Pleistocene Epoch divergence for the neotropical malaria vector Anopheles nuneztovari sensu lato. Am J Trop Med Hyg. 2011; 85(5): 857-67.

19. Marrelli MT, Floeter-Winter LM, Malafronte RS, Tadei WP, Lourenço-de-Oliveira R, Flores-Mendoza $\mathrm{C}$, et al. Amazonian malaria vector anopheline relationships interpreted from ITS2 rDNA sequences. Med Vet Entomol. 2005; 19(2): 208-18.
20. Ruiz F, Linton YM, Ponsonby DJ, Conn JE, Herrera M, Quinones ML, et al. Molecular comparison of topotypic specimens confirms Anopheles (Nyssorhynchus) dunhami Causey (Diptera: Culicidae) in the Colombian Amazon. Mem Inst Oswaldo Cruz. 2010; 105(7): 899-903.

21. Moreno M, Saavedra MP, Bickersmith SA, Lainhart W, Tong C, Alava F, et al. Implications for changes in Anopheles darlingi biting behaviour in three communities in the peri-Iquitos region of Amazonian Peru. Malar J. 2015; 14: 290.

22. Lounibos LP, Conn JE. Malaria vector heterogeneity in South America. American Entomologist. 2000; 46(4): 238-49.

23. de Arruda M, Carvalho MB, Nussenzweig RS, Maracic M, Ferreira AW, Cochrane AH. Potential vectors of malaria and their different susceptibility to Plasmodium falciparum and Plasmodium vivax in Northern Brazil identified by immunoassay. Am J Trop Med Hyg. 1986; 35(5): 873-81.

24. Tadei WP, Thatcher BD, Santos JM, Scarpassa VM, Rodrigues IB, Rafael MS. Ecologic observations on anopheline vectors of malaria in the Brazilian Amazon. Am J Trop Med Hyg. 1998; 59(2): 325-35.

25. Calderón G, Fernández R, Valle J. Especies de la fauna anofelina, su distribucion y algunas consideraciones sobre su abundancia e infectividad en el Peru. Rev Peru Epidemiol. 1995; 8(1): 5-23.

26. Matson R, Rios CT, Chávez CB, Gilman RH, Florin D, Sifuentes $\mathrm{VL}$, et al. Improved molecular technique for the differentiation of neotropical anopheline species. Am J Trop Med Hyg. 2008; 78(3): 492-8.

27. Vittor AY, Pan W, Gilman RH, Tielsch J, Glass G, Shields T, et al. Linking deforestation to malaria in the Amazon: characterization of the breeding habitat of the principal malaria vector, Anopheles darlingi. Am J Trop Med Hyg. 2009; 81: 5-12.

28. Reinbold-Wasson DD, Sardelis MR, Jones JW, Watts DM, Fernandez R, Carbajal F, et al. Determinants of Anopheles seasonal distribution patterns across a forest to periurban gradient near Iquitos, Peru. Am J Trop Med Hyg. 2012; 86(3): 459-63.

29. Hayes J, Calderón G, Falcon R, Zambrano V. Newly incriminated anopheline vectors of human malaria parasites in Junin Department, Peru. J Am Mosq Control Assoc. 1987; 3(3): 418-22.

30. Parker BS, Olortegui MP, Yori PP, Escobedo K, Florin D, Pinedo $\mathrm{SR}$, et al. Hyperendemic malaria transmission in areas of occupation-related travel in the Peruvian Amazon. Malar J. 2013; 12: 178.

31. Forattini OP. Entomologia médica. Vol. 1. São Paulo: Faculdade de Higiene e Sáude Publica; 1962. 662 pp.

32. Faran ME, Linthicum KJ. A handbook of the Amazonian species of Anopheles (Nyssorhynchus) (Diptera: Culicidae). Mosq Syst. 1981; 13: 1-81.

33. Consoli RA, Lourenço-de-Oliveira R. Principais mosquitos de importância sanitária no Brasil. Rio de Janeiro: Fiocruz; 1994. 228 pp.

34. Hiwat H, Bretas G. Ecology of Anopheles darlingi Root with respect to vector importance: a review. Parasit Vectors. 2011; 4: 177.

35. Folmer O, Black M, Hoeh W, Lutz R, Vrijenhoek R. DNA primers for amplification of mitochondrial cytochrome $\mathrm{c}$ oxidase subunit I from diverse metazoan invertebrates. Mol Mar Biol Biotechnol. 1994; 3(5): 294-9.

36. Hebert PD, Penton EH, Burns JM, Janzen DH, Hallwachs W. Ten species in one: DNA barcoding reveals cryptic species in the neotropical skipper butterfly Astraptes fulgerator. Proc Natl Acad Sci USA. 2004; 101(41): 14812-7.

37. Ratnasingham S, Hebert PDN. bold: the barcode of life data system (http://www.barcodinglife.org). Mol Ecol Notes. 2007; 7(3): 355-64.

38. Bickersmith SA, Lainhart W, Moreno M, Chu VM, Vinetz JM, Conn JE. A sensitive, specific and reproducible real-time poly- 
merase chain reaction method for detection of Plasmodium vivax and Plasmodium falciparum infection in field-collected anophelines. Mem Inst Oswaldo Cruz. 2015; 110(4): 573-6.

39. R Core Team. R: a language and environment for statistical computing. Vienna: R Foundation for Statistical Computing. 2018.

40. Pebesma EJ, Bivand RS. Classes and methods for spatial data in R. R News. 2005; 9-13.

41. Bivand R, Rundel C. rgeos: interface to geometry engine - open source ('GEOS'). R package version 0.3-28. 2018.

42. van Buuren S, Groothuis-Oudshoorn K. mice: multivariate imputation by chained equations in R. J Stat Softw. 2011; 45(3): 1-67.

43. Grund S, Robitzsch A, Luedtke O. mitml: Tools for Multiple Imputation in Multilevel Modeling. R package version 0.3-5. 2017.

44. Kearse M, Moir R, Wilson A, Stones-Havas S, Cheung M, Sturrock S, et al. Geneious basic: an integrated and extendable desktop software platform for the organization and analysis of sequence data. Bioinformatics. 2012; 28(12): 1647-9.

45. Edgar RC. MUSCLE: multiple sequence alignment with high accuracy and high throughput. Nucleic Acids Res. 2004; 32(5): 1792-7.

46. Kumar S, Stecher G, Tamura K. MEGA7: Molecular Evolutionary Genetics Analysis Version 7.0 for bigger datasets. Mol Biol Evol. 2016; 33(7): 1870-4.
47. Leigh JW, Bryant D. popart: full-feature software for haplotype network construction. Methods Ecol Evol. 2015; 6(9): 1110-6.

48. Bandelt HJ, Forster P, Rohl A. Median-joining networks for inferring intraspecific phylogenies. Mol Biol Evol. 1999; 16(1): 37-48.

49. Moreno M, Saavedra MP, Bickersmith SA, Prussing C, Michalski A, Rios CT, et al. Intensive trapping of blood-fed Anopheles darlingi in Amazonian Peru reveals unexpectedly high proportions of avian blood-meals. PLoS Negl Trop Dis. 2017; 11(2): e0005337.

50. Prussing C, Moreno M, Saavedra MP, Bickersmith SA, Gamboa $\mathrm{D}$, Alava F, et al. Decreasing proportion of Anopheles darlingi biting outdoors between long-lasting insecticidal net distributions in peri-Iquitos, Amazonian Peru. Malar J. 2018; 17(1): 86.

51. Elliott R. The influence of vector behavior on malaria transmission. Am J Trop Med Hyg. 1972; 21(5): 755-63.

52. Tadei WP, Thatcher BD. Malaria vectors in the Brazilian Amazon: Anopheles of the subgenus Nyssorhynchus. Rev Inst Med Trop São Paulo. 2000; 42(2): 87-94

53. Conde M, Pareja PX, Orjuela LI, Ahumada ML, Duran S, Jara JA, et al. Larval habitat characteristics of the main malaria vectors in the most endemic regions of Colombia: potential implications for larval control. Malar J. 2015; 14(1): 476. 